\title{
FATTY ACID COMPOSITION IN MEDICINAL MUSHROOMS (CRATERELLUS TUBAEFORMIS)
}

\author{
Lilko Dospatliev ${ }^{1}$, Miroslava Ivanova ${ }^{2}$, Zhana Petkova $^{3}$, Maria Angelova-Romova ${ }^{3}$, \\ Ginka Antova ${ }^{3}$ \\ ${ }^{1}$ Department of Pharmacology, Animal Physiology and Physiological Chemistry, Faculty of \\ Veterinary Medicine, Trakia University \\ Student campus, Stara Zagora 6000, Bulgaria, e-mail: Ikd@abv.bg \\ ${ }^{2}$ Department of Informatics and Mathematics, Trakia University, Stara Zagora, Bulgaria \\ ${ }^{3}$ Department of Chemical Technology, University of Plovdiv, Bulgaria \\ 24 Tzar Asen Street, Plovdiv 4000, Bulgaria
}

\begin{abstract}
Bulgaria has a very rich fungal flora due to its phytogeographical position. The screening of chemical content and active substances of mushrooms becomes an important subject not only for Bulgaria but also for all over the world. In the last decade, Analyses on phytochemical and biological activity of fungi have gradually increased as a result of improvement in the number and quality of facilities. In the scope of the present research, medicinal mushrooms; Craterellus tubaeformis was analyzed for fatty acid compositions by GC-FID, tocopherols by HPLC-fluorescence, and Oil content by Soxhlet. The ongoing research will lead to a new generation of foods, and will certainly promote their nutritional and medicinal use.
\end{abstract}

Keywords: Oil content, Fatty acid, Tocopherols, Craterellus tubaeformis, Batak mountain, Bulgaria.

\section{INTRODUCTION}

Different mushrooms were studied by the scientific community,in searching for new therapeutic alternatives, and the resultsproved their bioactive properties. Mushrooms are rich sources of nutraceuticals responsible for their antioxidant, antitumor, and antimicrobial properties. Besides their pharmacological features, wild mushrooms are becoming more important in our diet due to their nutritional value, related to the high protein and low fat/energy contents.

Craterellus tubaeformis is a beneficial nutrient for human health with high levels of vitamins $B$ and $C$ [1]. Natural antioxidants can be used as an effective tool against oxidative damage which can result in ageing and degenerative diseases [2]. Some mushrooms are an important source of natural antioxidants and essential fatty acids. Many studies have been conducted individually on fatty acids, antioxidant activities, mineral and trace elements of mushrooms [3,4]. But fatty acid composition of mushrooms have not been evaluated altogether.

Our objective was to evaluate the fatty acid composition wild edible medicinal mushroom specie (Craterellus tubaeformis) collected from Bulgaria.

\section{METHODS}

\subsection{Mushroom Samples}

Fifteen mushroom samples were collected in 2014 and 2017 from the Batak mountain by the authors themselves. 


\section{ART'TE

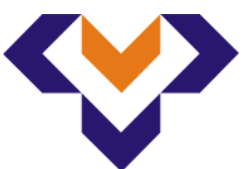 \\ Ipplied Resseirlohes in Technics, Technologies and Bductation \\ Journal of the Faculty of Technics and Technologies, Trakia University https://sites.google.com/a/trakia-uni.bg/artte/}

The Batak mountain is located in western Rhodopes. Its western border is defined by the Chepinska river, the southern border - by Dospatska river and Dospat dam, the eastern border - by Vacha river and the northern border - by the Thracian Plane (GPS41 ${ }^{\circ} 46^{\prime} 02.66^{\prime \prime} \mathrm{N}$ $24^{\circ} 08^{\prime} 48.4^{\prime \prime E}$ ). The regions is industry-free and is characterised with forests, land and low buildings.

\subsection{Reagents}

All chemicals were at least of analytical-reagent grade. Water was de-ionized in a Milli- $Q$ system (Millipore, Bedford, MA, USA) to a resistivity of $18.2 \mathrm{M} \Omega \mathrm{cm}$.

All plastic and glassware were cleaned by soaking in diluted HNO3 $(1 / 9, v / v)$ and were rinsed with distilled water prior to use.

\subsection{Determination of Oil content}

The seeds (10 g sample) were air-dried and the oil was extracted with $\mathrm{n}$-hexane in Soxhlet for $8 \mathrm{~h}$ [5]. The solvent was partly removed in rotary vacuum evaporator, the residue was transferred in pre-weight glass vessels and the rest of the solvent was removed under stream of nitrogen to a constant weight to determine the oil content.

\subsection{Determination of Fatty acids}

The fatty acid composition was determined by gas chromatography after transmethylation of the sample with $2 \% \mathrm{H}_{2} \mathrm{SO}_{4}$ in absolute $\mathrm{CH}_{3} \mathrm{OH}$ at $50^{\circ} \mathrm{C}$ [6]. Fatty acid methyl esters (FAME) were purified by thin-layer chromatography (TLC) on $20 \times 20 \mathrm{~cm}$ plates covered with $0.2 \mathrm{~mm}$ silica gel $60 \mathrm{G}$ (Merck) layer with mobile phase n-hexane:diethyl ether (97:3, v/v). GC was performed on a HP 5890 series II (Hewlett Packard GesmbH, Vienna, Austria) gas chromatograph equipped with a $75 \mathrm{~m} \times 0.18 \mathrm{~mm}$ (I.D.) $\times 25 \mu \mathrm{m}$ (film thickness) capillary column Supelco and a flame ionization detector. The column temperature was programmed from $140^{\circ} \mathrm{C}$ (5 $\left.\mathrm{min}\right)$, at $4^{\circ} \mathrm{C} / \mathrm{min}$ to $240^{\circ} \mathrm{C}(3 \mathrm{~min})$; injector and detector temperatures were kept at $250^{\circ} \mathrm{C}$. Hydrogen was the carrier gas at a flow rate $0.8 \mathrm{~mL} / \mathrm{min}$; split was 1:50. Identification of fatty acids was performed by comparison of retention times with those of a standard mixture of fatty acids subjected to GC under identical experimental conditions [7].

\subsection{Determination of Tocopherols}

Tocopherols were determined directly in the oil by high performance liquid chromatography (HPLC) on a Merck-Hitachi (Merck, Darmstadt, Germany) instrument equipped with $250 \mathrm{~mm}$ x $4 \mathrm{~mm}$ Nucleosil Si 50-5 column (Merck, Darmstadt, Germany) and fluorescent detector Merck-Hitachi F 1000. The operating conditions were as follows: mobile phase of n-hexane: dioxan, 96:4 (by volume), flow rate $1.0 \mathrm{ml} / \mathrm{min}$, excitation $295 \mathrm{~nm}$, emission $330 \mathrm{~nm} .20 \mu \mathrm{l} \%$ solution of crude oil were injected. Tocopherols were identified by comparing the retention times with those of authentic individual tocopherols. The tocopherol content was calculated on the base of tocopherol peak areas in the sample vs. tocopherol peak area of standard tocopherol solution [8].

\subsection{Statistical}

SPSS (Statistical Package for Social Science) program for Windows was used for statistical data processing. 


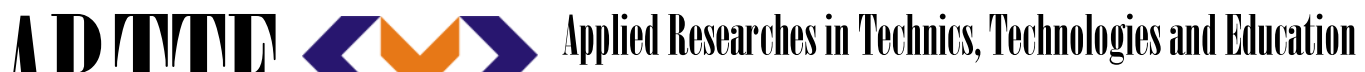 Journal of the Faculty of Technics and Technologies, Trakia University https://sites.google.com/a/trakia-uni.bg/artte/}

\section{EXPERIMENTAL}

The oil content, Tocopherol, Fatty acid compositions of mushrooms (Craterellus tubaeformis) were given in Table 1.

Chromatogram of FAMEs of mushroom (Craterellus tubaeformis) is given in Figure 1.

Table 1. Oil content, Tocopherol, Fatty acid composition of mushrooms (Craterellus tubaeformis)

\begin{tabular}{|c|c|c|}
\hline \multicolumn{3}{|c|}{ Mushrooms (Craterellus tubaeformis) } \\
\hline & Oil content, \% & 4.1 \\
\hline \multicolumn{2}{|c|}{$\alpha$-Tocopherol, \% } & 51.7 \\
\hline \multicolumn{2}{|c|}{$\gamma$-Tocopherol, \% } & - \\
\hline \multicolumn{2}{|c|}{$\delta$-Tocopherol, \% } & 48.3 \\
\hline \multicolumn{2}{|c|}{ Total tocopherols, $\mathrm{mg} / \mathrm{kg}$} & 17 \\
\hline \multicolumn{3}{|c|}{ Fatty acids, $\%$} \\
\hline$C_{12: 0}$ & Lauric & - \\
\hline$C_{14: 0}$ & Myristic & 0.3 \\
\hline$C_{15: 0}$ & Pentadecanoic & 0.6 \\
\hline$C_{16: 0}$ & Palmitic & 17.7 \\
\hline$C_{16: 1}$ & Palmitoleic & 0.8 \\
\hline$C_{17: 0}$ & Margaric & 0.3 \\
\hline $\mathrm{C}_{18: 0}$ & Stearic & 14.5 \\
\hline$C_{18: 1}$ & Oleic & 54.9 \\
\hline$C_{18: 2}$ & Linoleic & 7.5 \\
\hline$C_{18: 3}$ & Linolenic & 0.2 \\
\hline$C_{20: 0}$ & Arachidic & 0.6 \\
\hline$C_{20: 1}$ & Gadoleic & 0.6 \\
\hline$C_{20: 2}$ & Eicosadienoic & 0.9 \\
\hline $\mathrm{C}_{20: 3}$ & Eicosatrienoic & 0.1 \\
\hline $\mathrm{C}_{20: 4}$ & Arachidonic & 0.1 \\
\hline $\mathrm{C}_{20: 5}$ & Eicosapentaenoic & 0.4 \\
\hline $\mathrm{C}_{22: 0}$ & Behenic & 0.5 \\
\hline & SFA & 34.5 \\
\hline & UFA & 65.5 \\
\hline & MUFA & 56.3 \\
\hline & PUFA & 9.2 \\
\hline
\end{tabular}

- Not identified; SFA - saturated fatty acids;

UFA - unsaturated fatty acids;

MUFA - monounsaturated fatty acids;

PUFA - polyunsaturated fatty acids.

IRTIIE Vol. 6, No. 1, 2018 ISSN 1314-8788 (print), ISSN 1314-8796 (online), doi: 10.15547/artte.2018.01.005 


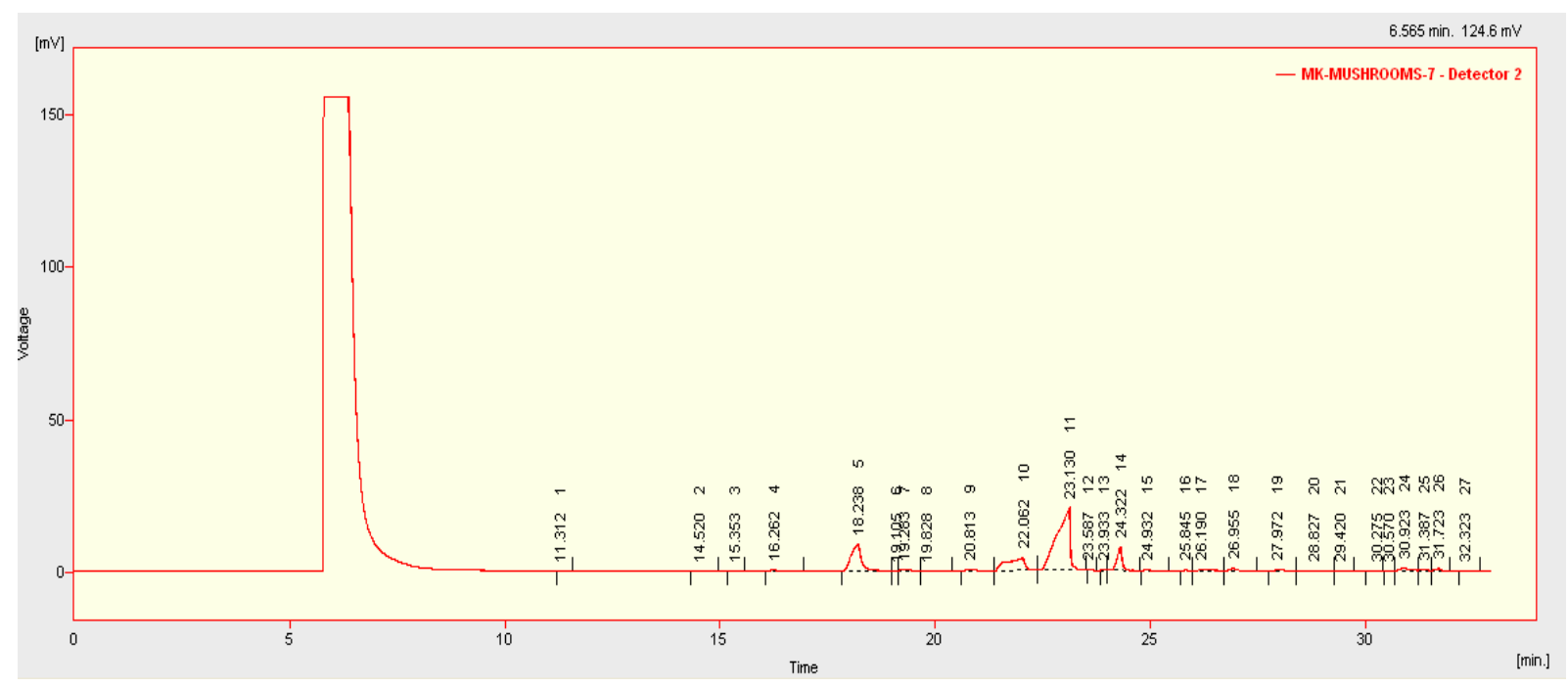

Figure 1.

Chromatogram of FAMEs of mushroom (Craterellus tubaeformis)

1 - Lauric acid; 2 - Myristic acid; 4 - Pentadecanoic acid; 5 - Palmitic acid; 7 - Palmitoleic acid; 8 - Margaric acid; 10 - Stearic acid; 11 - Oleic acid; 14 - Linoleic acid; 15 - Arachidic acid; 16 - Linolenic acid; 17 - Gadoleic acid; 18 - Eicosadienoic acid; 19 - Behenic acid; 20 - Eicosatrienoic acid; 21 - Arachidonic acid; 25 - Eicosapentaenoic acid

\section{RESULTS}

Oil content of the sample was relatively low (4.1\%) but higher than those of other species of mushrooms. The results obtained in this study are consistent with the previously reported results in the literature $[4,9]$. In addition to linoleic acid, the other fatty acids such as oleic acid, palmitic acid, penthadecenoic acid and linoelaidic acids were also found in the mushroom samples.

Total tocopherol content was found to be $17 \mathrm{mg} / \mathrm{kg}$ and the amount of $\alpha$ - and $\delta$-tocopherol was about $50.0 \%$.

Unsaturated fatty acids prevailed in the oil from mushroom (65.5\%) and the content of MUFA consisted of $56.3 \%$. On the other hand, the amount of PUFA was much lower (9.2\%). Oleic acid predominated in the triacylglycerols $(54.9 \%)$, followed by palmitic $(17.7 \%)$ and stearic acid (14.5\%). The quantity of linoleic acid was found to be $7.5 \%$ and the other fatty acids were from 0.1 to $0.9 \%$.

\section{CONCLUSIONS}

The ongoing research will lead to a new generation of foods, and will certainly promote their nutritional and medicinal use. 


\section{ARITIE $Y$}

Ipplied Resseirlohes in Technics, Technologies and Bductation Journal of the Faculty of Technics and Technologies, Trakia University https://sites.google.com/a/trakia-uni.bg/artte/

\section{REFERENCES}

[1] Muszynska, B., K. Sulkowska-Ziaja, and H. Ekiert, 2013. Phenolic acids in selected edible basidiomycota species: Armillaria mellea, Boletus badius, Boletus edulis, Cantharellus cibarius, Lactarius deliciosus AND Pleurotus ostreatus. Acta Sci Pol-Hortoru, 12, 107116.

[2] Muka, T., N. Stringa, A. Brahimaj, A. Zaciragic, B. Kraja, A. Dehghan, A Hofman, JC Kiefte-De Jong, and O.H. Franco, 2015. Total antioxidant capacity of diet and plasma markers of oxidant-antioxidant status are associated with low-grade chronic inflammation: the rotterdam study. http://www.erasmusage.com/wp-content/uploads/2015/09/womenshealth-ESC-2015-Muka-total-anitoxidant- capacity. pdf. Accessed 3 Fabruary 2017

[3] Falandysz, J., and M. Drewnowska, 2015. Macro and trace elements in Common Chanterelle (Cantharellus cibarius) mushroom from the European background areas in Poland: Composition, accumulation, dietary exposure and data review for species. J Environ Sci Heal B, 50, 374-387.

[4] Goyal, R., RB. Grewal, and RK Goyal, 2015. Fatty Acid Composition and Dietary Fibre Constituents of Mushrooms of North India. Emir J Food Agric, 27, 927-930.

[5] ISO 659:2014. Oilseeds. Determination of oil content (Reference method).

[6] ISO 12966-2:2011. Animal and vegetable fat and oils. Gas chromatography of fatty acid methyl esters - Part 2: Preparation of methyl esters of fatty acids.

[7] ISO 12966-1:2014. Animal and vegetable fats and oils. Gas chromatography of fatty acid methyl esters - Part 1: Guidelines on modern gas chromatography of fatty acid methyl esters.

[8] ISO 9936:2016. Animal and vegetable fats and oils. Determination of tocopherol and tocotrienol contents by high-performance liquid chromatography.

[9] Yilmaz, N., M. Solmaz, I.Turkekul, and M. Elmastas, 2006. Fatty acid composition in some wild edible mushrooms growing in the middle Black Sea region of Turkey. Food Chem., 99, 168-174. 